\title{
The Effect of Hydrogen Addition on Low-Temperature Combustion of Light Hydrocarbons and Alcohols
}

\author{
Fekadu Mosisa Wako, Gianmaria Pio@ and Ernesto Salzano *(i) \\ Dipartimento di Ingegneria Civile, Chimica, Ambientale e dei Materiali, Università di Bologna, via Terracini 28, \\ 40131 Bologna, Italy; fekadumosisa.wako2@unibo.it (F.M.W.); gianmaria.pio@unibo.it (G.P.) \\ * Correspondence: ernesto.salzano@unibo.it
}

Received: 25 June 2020; Accepted: 21 July 2020; Published: 25 July 2020

check for updates

\begin{abstract}
Hydrogen is largely considered as an attractive additive fuel for hydrocarbons and alcohol-fueled engines. Nevertheless, a complete understanding of the interactions between blended fuel mechanisms under oxidative conditions at low initial temperature is still lacking. This study is devoted to the numerical investigation of the laminar burning velocity of hydrogen-hydrocarbon and hydrogen-alcohol fuels under several compositions. Estimations were compared with experimental data reported in the current literature. Additionally, the effects of hydrogen addition on engine performance, $\mathrm{NO}_{X}$, and other pollutant emissions of the mentioned fuels have been thermodynamically analyzed. From the study, it has been observed that the laminar burning velocity of the fuel mixtures increased with increasing hydrogen fractions and the peak value shifted to richer conditions. Besides, hydrogen fraction was found to increase the adiabatic flame temperatures eventually favoring the $\mathrm{NO}_{\mathrm{X}}$ formation for all fuel blends except the acetylene-hydrogen-air mixture where hydrogen showed a reverse effect. Besides, hydrogen is also found to improve the engine performances and helps to surge thermal efficiency, improve the combustion rate, and lessen other pollutant emissions such as $\mathrm{CO}, \mathrm{CO}_{2}$, and unburned hydrocarbons. The model predicted well and in good agreement with the experimental data reported in the recent literature.
\end{abstract}

Keywords: hydrogen; combustion; laminar burning velocity; kinetic mechanisms; alkanes combustion; alcohols combustion

\section{Introduction}

Due to the rapid reduction of fossil fuel sources and the alarming air pollution, several clean, reliable, and energy-efficient fuel sources are emerging [1,2]. Among the others, hydrogen energy is largely considered as a promising alternative fuel, because of its $\mathrm{CO}_{2}$-free emission and wide flammability range, together with its easiness in production [3]. In contrast, its elevated reactivity and heat of combustion are challenging for application. Additionally, transporting the gas and its large-scale distribution system represent a major drawback. To tackle these issues and for the convenient use of hydrogen, blending with less reactive fuel has been considered in the last years. Indeed, the elevated reactivity of hydrogen makes this species the best additive to improve lean combustion features and reduce engine emissions [4,5]. However, the hydrogen addition requires a detailed characterization of the overall reactivity and its effects on pollutants' production. In this sense, the evaluation of the laminar burning velocity represents an essential step because it is a key combustion parameter representing the reactivity, exothermicity, diffusivity, flame flashback, and blow off trends of the fuel [6]. Eventually, measuring the laminar burning velocity at standard temperature $(298 \mathrm{~K})$ and pressure $(1 \mathrm{~atm})$ is vital for model validation.

In the past few decades, the laminar burning velocities of several light alkane-hydrogen-air mixtures, including natural gas (as a mixture of methane, ethane, and propane) at various temperatures 
and pressures have been measured and predicted either for model validation or combustion systems optimization [7]. A brief overview of the available data is given in the following Table 1.

Table 1. List of some of the experimental laminar burning velocity data available in the current literature for alkanes/hydrogen/air mixtures at ambient temperature and pressure.

\begin{tabular}{|c|c|c|c|}
\hline Author (s) & Fuel Composition & Equivalence Ratio (-) & Technique \\
\hline Liu et al. [8] & $\mathrm{CH}_{4}+\mathrm{H}_{2}$ & $0.6-2.2$ & Combustion burner \\
\hline Salzano et al. [9] & $\begin{array}{l}\mathrm{CH}_{4}+\mathrm{H}_{2} \\
\mathrm{C}_{3} \mathrm{H}_{8}+\mathrm{H}_{2}\end{array}$ & $0.6-2.0$ & Heat flux burner \\
\hline Law and Kwon [10] & $\begin{array}{c}\mathrm{CH}_{4}+\mathrm{H}_{2} \\
\mathrm{C}_{3} \mathrm{H}_{8}+\mathrm{H}_{2}\end{array}$ & 1.0 & Combustion chamber \\
\hline Nilsson et al. [11] & $\begin{array}{c}\mathrm{CH}_{4}+\mathrm{H}_{2} \\
\mathrm{C}_{2} \mathrm{H}_{6}+\mathrm{H}_{2} \\
\mathrm{C}_{3} \mathrm{H}_{8}+\mathrm{H}_{2} \\
\mathrm{CH}_{4}+\mathrm{C}_{2} \mathrm{H}_{6}+\mathrm{H}_{2} \\
\mathrm{CH}_{4}+\mathrm{C}_{3} \mathrm{H}_{8}+\mathrm{H}_{2} \\
\mathrm{CH}_{4}+\mathrm{C}_{2} \mathrm{H}_{6}+\mathrm{C}_{3} \mathrm{H}_{8}+\mathrm{H}_{2}\end{array}$ & $0.6-1.7$ & Heat flux burner \\
\hline Dong et al. [12] & $\mathrm{C}_{2} \mathrm{H}_{6}+\mathrm{H}_{2}$ & 0.6 & Counterflow burner \\
\hline Tang et al. [13] & $\mathrm{C}_{3} \mathrm{H}_{8}+\mathrm{H}_{2}$ & $0.6-1.6$ & Combustion bomb \\
\hline Milton and Keck [14] & $\begin{array}{c}\mathrm{CH}_{4}+\mathrm{H}_{2} \\
\mathrm{C}_{3} \mathrm{H}_{8}+\mathrm{H}_{2}\end{array}$ & 1.0 & Combustion bomb \\
\hline Huang et al. [15] & $\mathrm{CH}_{4}+\mathrm{C}_{2} \mathrm{H}_{6}+\mathrm{C}_{3} \mathrm{H}_{8}+\mathrm{H}_{2}$ & $0.6-1.4$ & Combustion bomb \\
\hline Coppens [16] & $\mathrm{CH}_{4}+\mathrm{C}_{2} \mathrm{H}_{6}+\mathrm{C}_{3} \mathrm{H}_{8}+\mathrm{H}_{2}$ & $0.7-1.4$ & Heat flux burner \\
\hline Hermanns et al. [17] & $\mathrm{CH}_{4}+\mathrm{H}_{2}$ & $0.6-1.5$ & Heat flux burner \\
\hline Hu et al. [18] & $\mathrm{CH}_{4}+\mathrm{H}_{2}$ & $0.6-1.3$ & Combustion chamber \\
\hline Christensen and Moah [19] & $\mathrm{CH}_{4}+\mathrm{H}_{2}$ & $0.6-1.7$ & Heat flux burner \\
\hline Wu et al. [20] & $\mathrm{C}_{2} \mathrm{H}_{6}+\mathrm{H}_{2}$ & $0.7,1.0,1.6$ & Spherical flame \\
\hline Sepman et al. [21] & $\begin{array}{l}\mathrm{C}_{2} \mathrm{H}_{6}+\mathrm{H}_{2} \\
\mathrm{C}_{3} \mathrm{H}_{8}+\mathrm{H}_{2} \\
\end{array}$ & 1.3 & Heat flux burner \\
\hline Yu et al. [22] & $\begin{array}{c}\mathrm{CH}_{4}+\mathrm{H}_{2} \\
\mathrm{C}_{3} \mathrm{H}_{8}+\mathrm{H}_{2}\end{array}$ & $0.5-1.4$ & Counterflow chamber \\
\hline
\end{tabular}

Mixing hydrogen with alkenes, alkynes or alcohols is also important for better performance of engine fuels. Acetylene is gaining more and more attention because, compared with other hydrocarbon fuels; it has a higher adiabatic flame temperature, a higher burning speed, and a smaller quenching distance [23]. Besides, methanol and ethanol are promising oxygenated and renewable fuels, useful to mitigate $\mathrm{CO}$ [24] and HC [25] emissions. Their higher latent heat of vaporization aids to hinder $\mathrm{NO}_{X}$ emissions [26]. However, the problems related to cold start [27] and an unregulated emission of $\mathrm{CH}_{2} \mathrm{OH}$ limit the adoption of pure alcohol-fueled engines [28], thus attracting the investigation on hydrogen addition [29]. Hence, several experimental investigations have involved these mixtures, as reported in Table 2.

Table 2. List of some of the experimental laminar burning velocity available in the current literature for alkene/hydrogen and alcohol/hydrogen mixtures with air at ambient temperature and pressure.

\begin{tabular}{cccc}
\hline Author (s) & Fuel Composition & Equivalence Ratio (-) & Technique \\
\hline Milton and Keck [14] & $\mathrm{C}_{2} \mathrm{H}_{2}+\mathrm{H}_{2}$ & 1.0 & Combustion chamber \\
Wu et al. [20] & $\mathrm{C}_{2} \mathrm{H}_{2}+\mathrm{H}_{2}$ & $0.7 ; 1.0 ; 1.6$ & spherical flame \\
Xiao et al. [30] & $\mathrm{CH}_{3} \mathrm{OH}+\mathrm{H}_{2}$ & $0.8 ; 1.0: 1.2$ & Combustion chamber \\
Li et al. [2012] [31] & $\mathrm{C}_{2} \mathrm{H}_{5} \mathrm{OH}+\mathrm{H}_{2}$ & $0.6-1.6$ & Spherical flame \\
Peng et al. [32] & $\mathrm{C}_{2} \mathrm{H}_{5} \mathrm{OH}+\mathrm{H}_{2}$ & $0.8 ; 1.0 ; 1.2$ & Combustion burner \\
\hline
\end{tabular}


The lean combustion feature of hydrogen can also offer advantages such as improving engine performance, reducing combustion duration, improving fuel homogeneity, reducing $\mathrm{CO}, \mathrm{CO}_{2}$, and unburned hydrocarbons (UHC) emissions. However, it ends up with more $\mathrm{NO}_{\mathrm{X}}$ formation due to the increase in combustion temperature [33]. Shin et al. [34] reported the effects of different hydrogen fractions on diesel engine performance and emission characteristics. The study shows that adding hydrogen can improve the combustion efficiency of engines. Saravanan and Nagarajan [35] studied the impact of hydrogen concentrations on hydrocarbon emission and observed a considerable reduction in UHC and other pollutants from $56 \mathrm{ppm}$ to the lowest value (31 ppm) at higher hydrogen fractions. Catapano et al. [36] performed a comprehensive analysis of the effects of hydrogen addition on ethanol, methane, and their mixtures on engine performance and $\mathrm{NO}_{X}$ emissions during port fuel injection (PFI) engine combustion. They found that due to the faster combustion rate and the increase in the local temperature associated with hydrogen, the addition of hydrogen to both fuels increased engine efficiency and favored $\mathrm{NO}_{X}$ formation.

Coming to the computational side, extensive studies on simulations of premixed fuel mixture flames have been reported [7]. Most of these calculations were performed using CHEMKIN [37] or COSILAB [38] laminar premixed flame codes, in which a detailed kinetic scheme was applied [39]. These efforts are intended to reproduce the experimental results and to advance insights. It has been agreed that reaction chemistry that relies on $\mathrm{H}$ radicals plays a role in both, the promoting effect of hydrogen addition on methane combustion [40] and the inhibiting effect of methane on hydrogen [41]. The numerical modeling study of lean premixed hydrogen-ethane-air flat flame at atmospheric pressure was conducted by Haynes et al. [42]. Law and Kwon [10] studied numerical prediction of the laminar burning velocity of propane-hydrogen-air mixtures at room temperature and atmospheric pressure to quantify the degree of reduction in combustion rate caused by the addition of hydrocarbons, to study the potential for improving hydrogen safety and engine performance by adding hydrocarbons to a hydrogen-air mixture based on a detailed hydrocarbon oxidation mechanism (for $\mathrm{C}_{2}$-and $\mathrm{C}_{3}$-hydrocarbons) chemistry developed by Qin et al. [43]. Recently, Al-Hamamre and Yamin [44] performed chemical kinetic calculations for acetylene-hydrogen-air and ethanol-hydrogen-air mixtures and reported that $\mathrm{H}$, $\mathrm{O}$, and $\mathrm{OH}$ radicals are the most important reactive species for increasing the laminar burning velocity. Xiao et al. [32] recently performed a numerical study of the laminar burning velocity of methanol-hydrogen-air mixtures under various pressures using CHEMKIN code and the detailed kinetic mechanism developed by NUI [45]. The effect of hydrogen addition on the laminar burning velocity of methanol-air mixtures has been numerically studied by Gong et al. [46]. The results showed that the addition of hydrogen accelerates the oxidation of methanol and reduces $\mathrm{CH}_{2} \mathrm{O}$ and $\mathrm{NO}$ emissions. Additionally, the effect of the hydrogen-methanol mixture on the performance of spark ignition engines has been numerically studied by Gong et al. [47] and Ji et al. [48]. The study revealed higher flame propagation speed, higher cylinder temperature and pressure, and lower carbon monoxide, formaldehyde, and unburned methanol. In this view, the current study focuses on the evaluation of the additivity effects of hydrogen on the laminar burning velocity of methane, ethane, propane, acetylene, methanol, and ethanol. A numerical approach was adopted for the identification of the major differences in the combustion paths attributable to the hydrogen addition and the outcome of the mixture on engine efficiency, $\mathrm{NO}_{\mathrm{X}}$ formation, and pollutant emissions are predicted.

In this paper, the laminar burning velocity of methane, ethane, acetylene, propane, methanol, and ethanol were evaluated at different conditions. The compositions of the unburned mixture were expressed in terms of equivalence ratio $(\varphi)$ and enrichment factor $(E)$, as defined in Equations (1) and (2).

$$
\begin{gathered}
\varphi=\sum \frac{\frac{m_{f}}{m_{O x}}}{\left(\frac{m_{f}}{m_{O x}}\right)_{s t}} \\
E_{h}=\frac{z_{h}}{\sum z_{f}}
\end{gathered}
$$


where $m$ and $z$ represent the mole fraction of the fuel/air or fuel only mixtures, respectively, and the subscripts $f, o x$, st, and $h$ stand for fuel species, oxidant, stoichiometric conditions, and hydrogen (intended as secondary species in this work).

\section{Materials and Methods}

The numerical simulations of laminar burning velocity were conducted with the help of the detailed kinetic mechanism developed by the University of Bologna (KiBo) [49] because it has been reported in previous studies that the mechanism represents an optimized tool for the evaluation of light hydrocarbons (i.e., lighter than $\mathrm{C}_{4}$ ) in a wide range of reaction conditions $[50,51]$. This mechanism is composed of $\sim 125$ species and $\sim 600$ elemental reactions describing the chemistry of the hydrocarbons in a wide range of conditions. Thermodynamic library including relevant properties per each species (e.g., enthalpy of formation, entropy, and heat capacity), together with a kinetic library mainly listing hydrogen abstraction/addition, disproportionation, and oxygen addition reactions; forms the adopted kinetic mechanism. The effect of temperature on the considered thermodynamic properties was expressed in terms of NASA polynomial coefficients calculated by ab initio calculations [52], either at low- (i.e., 200-1000 K) or high- (i.e., 1000-3000 K) temperature intervals. This mechanism has been developed by means of a hierarchical approach [53], meaning that the content of the implemented kinetic library can be distinguished in terms of the number of carbon atoms of reactants. In other words, a core combustion sub-model including $C_{0}$ species only is integrated by primary reactions of $C_{1}$, $\mathrm{C}_{2}, \mathrm{C}_{3}$, and $\mathrm{C}_{4}$ to account for the hydrocarbons' chemistry, nitrogen- and sulfur-containing reactants for nonhydrocarbon chemistry. The size of each group expressed in percentage can be displayed in Figure 1.

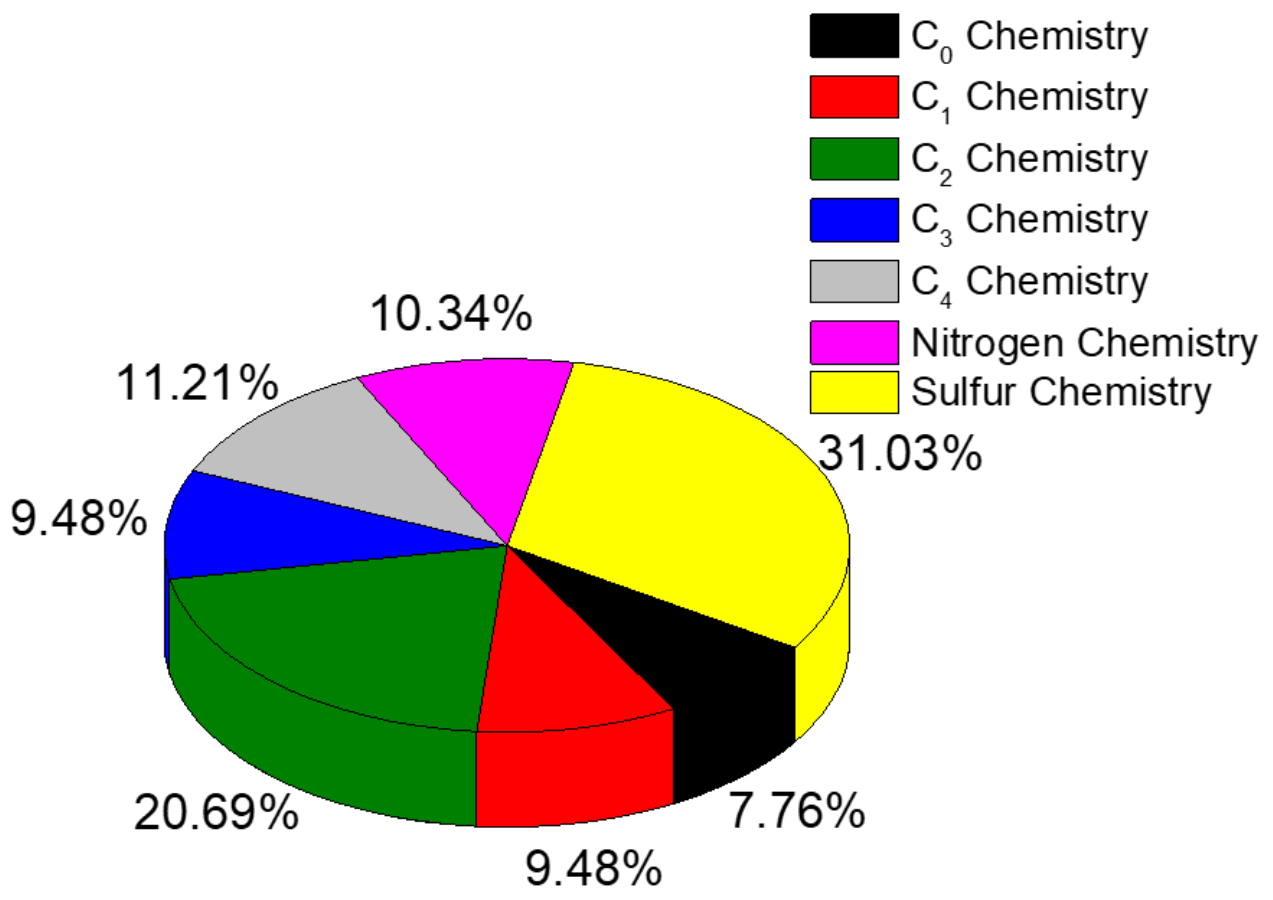

Figure 1. Composition of the kinetic library included in the detailed kinetic mechanism adopted in this work.

This mechanism was implemented in a monodimensional, adiabatic, premixed, and laminar flame to account for thermal and kinetic aspects only. To this aim, the open-source code Cantera [54] was employed. Traditional mass balances for each species included in KiBo, together with energy balance, were solved in a one-dimensional, discretized domain assuming steady-state conditions. Threshold values ruling the discretization process (referred to as grid parameters from now on) were set to 
avoid abrupt variations in obtained results between adjacent cells. More specifically, the adopted grid parameters were ratio equal to 3 , the slope was equal to 0.07 , and the curve was equal to 0.14 ; for the refiner function, the relative error criteria $(R T o l)$ and absolute error criteria $(A T o l)$ equal to $1.0 \times 10^{-9}$ and $1.0 \times 10^{-14}$ for the steady-state problem and $1.0 \times 10^{-5}$ and $1.0 \times 10^{-14}$ for a time-stepping problem, respectively. These values result in a typical grid of 250-350 points and are selected since previous studies have indicated these values to be optimized in terms of results accuracy and computational costs for the calculation of kinetic-related parameters [55] and thermodynamic properties [56]. The adiabatic flame temperature and burned compositions were calculated based on the abovementioned settings as a result of energy and mass balances. The obtained results were adopted for the estimation of the key performance indicators (KPIs) accounting for the environmental, chemical aspects, and maturity of the models, separately. The environmental KPI (eKPI) was calculated considering the sum of the emitted quantity of the most relevant pollutants (e.g., $\mathrm{CO}, \mathrm{CO}_{2}, \mathrm{UHC}$, soot precursors, and $\mathrm{NO}_{\mathrm{X}}$ ) expressed in mole fraction $(m)$ scaled by the corresponding global warming potential (GWP) published by the environmental protection agency [57], as reported in the following equation:

$$
\mathrm{eKPI}=\sum \mathrm{GWP}_{i} \cdot m_{i} \cdot \frac{\Delta H_{c, f u e l}}{\Delta H_{c, h 2}}
$$

The ratio of the heat of combustion of the investigated fuel and hydrogen, selected as a reference, was multiplied to reduce the effect of chemical structure on eKPI. The chemical KPI (cKPI) was intended as the increase in laminar burning velocity due to the hydrogen addition to the pure primary fuel. Eventually, the maturity of the model (mKPI) was evaluated by comparing the experimental measurements of the laminar burning velocity with the corresponding estimations and equalized to the coefficient of determination $\mathrm{R}^{2}$ of the resulting curve.

\section{Results}

The results of the numerical simulation of the laminar burning velocity of different fuel components with the addition of various hydrogen fractions under different conditions as obtained by using the detailed kinetic mechanism and the comparison with the experimental data reported in the recent literature are reported in Figure 2.

The predictions by the model fitted quite well with the experimental data at all conditions and compositions. The details of each component are discussed here below.

The burning velocity was found to linearly increase with hydrogen concentration either in lean or stoichiometric compositions for light alkanes. This is because increasing hydrogen concentration in the fuel mixture results in an increase in $\mathrm{H}$ radical generation in the flame front region which eventually increases overall reaction rates. Moreover, the higher thermal effect (chemical energy) of acetylene combined with the transport effect due to $\mathrm{H}$ radicals diffusion associated with hydrogen fraction contributed to the increment of laminar burning velocity. 

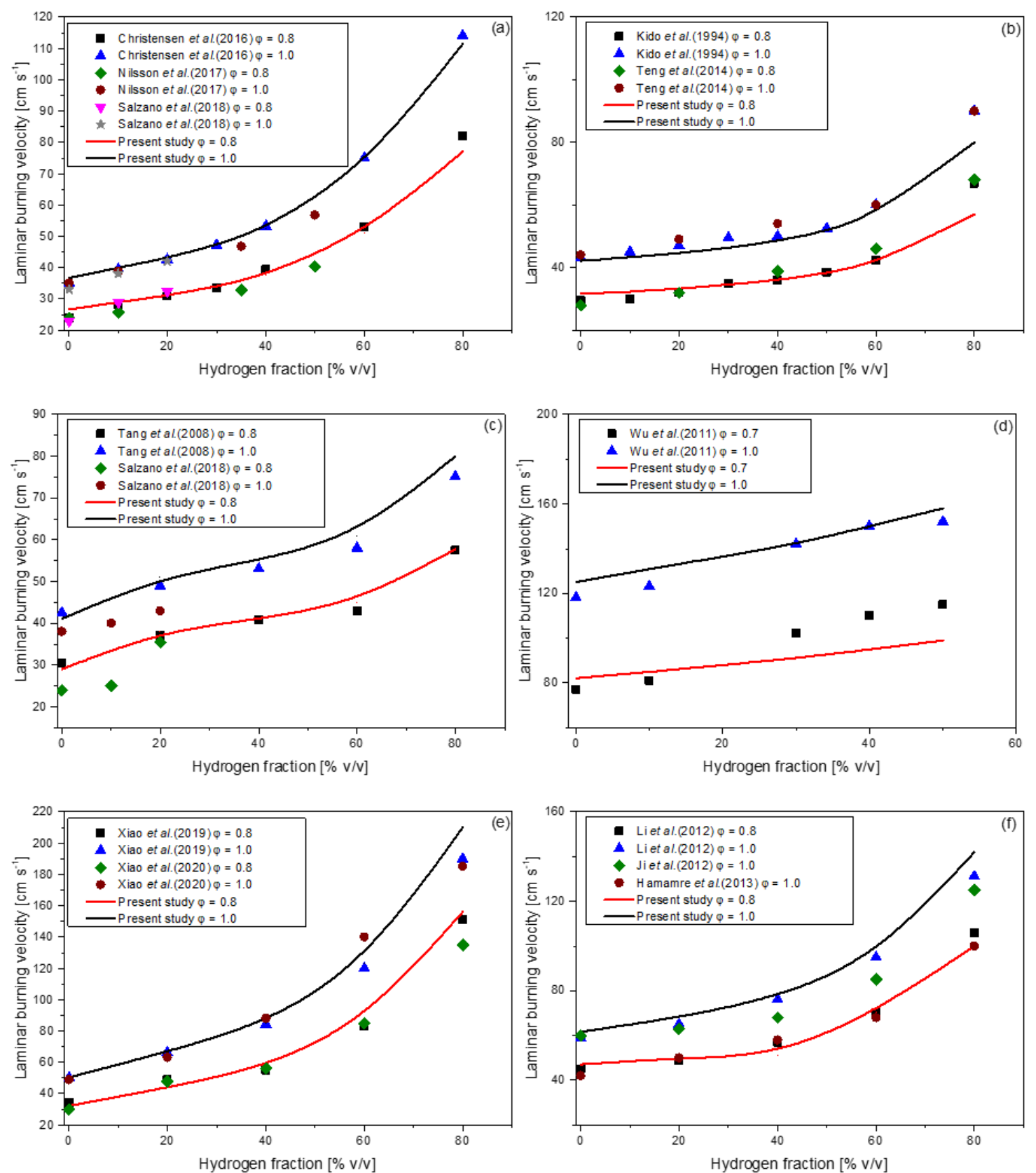

Figure 2. Effect of hydrogen fraction on laminar burning velocity of methane (a) $[9,11]$, ethane (b) [58,59], propane (c) [9,13], acetylene (d) [20,44], methanol (e) [30,32], and ethanol (f) [7] for lean and stoichiometric mixtures with air.

It is worth noting that ethane presents a different trend with respect to the other alkanes, thus confirming the peculiarity of its chemistry. Indeed, its laminar burning velocity is considerably less affected by hydrogen addition. This discrepancy can be attributed to the tendency to produce larger laminar burning velocity as pure fuel, as well, indicating a more efficient combustion mechanism. On the other side, the overall reactivity of oxygenated species is strongly augmented once hydrogen is added. Besides, the laminar burning velocity of the methanol-air mixture is influenced more with the hydrogen fraction than ethanol which is due to a high $\mathrm{H} / \mathrm{C}$ ratio of methanol. From a chemical point of view, this implies that the presence of an alcoholic functional group makes the compounds more prone to be activated by the molecular hydrogen. This aspect, together with the well-known relevance of 
hydrogen atom abstraction by small radicals in ignition phenomena, suggests that hydrogen-containing radicals dominate the primary reaction of alcohols. Hence, the reaction $\mathrm{ROH}+\mathrm{O}_{2} \leftrightarrow \mathrm{RO}+\mathrm{HO}_{2}$, which is typically considered as one of the major paths at low temperature [60], can be neglected for the investigated conditions.

Figure 3 shows the comparison of experimentally obtained laminar burning velocities and their respective computed values for different fuel species at the stoichiometric condition.

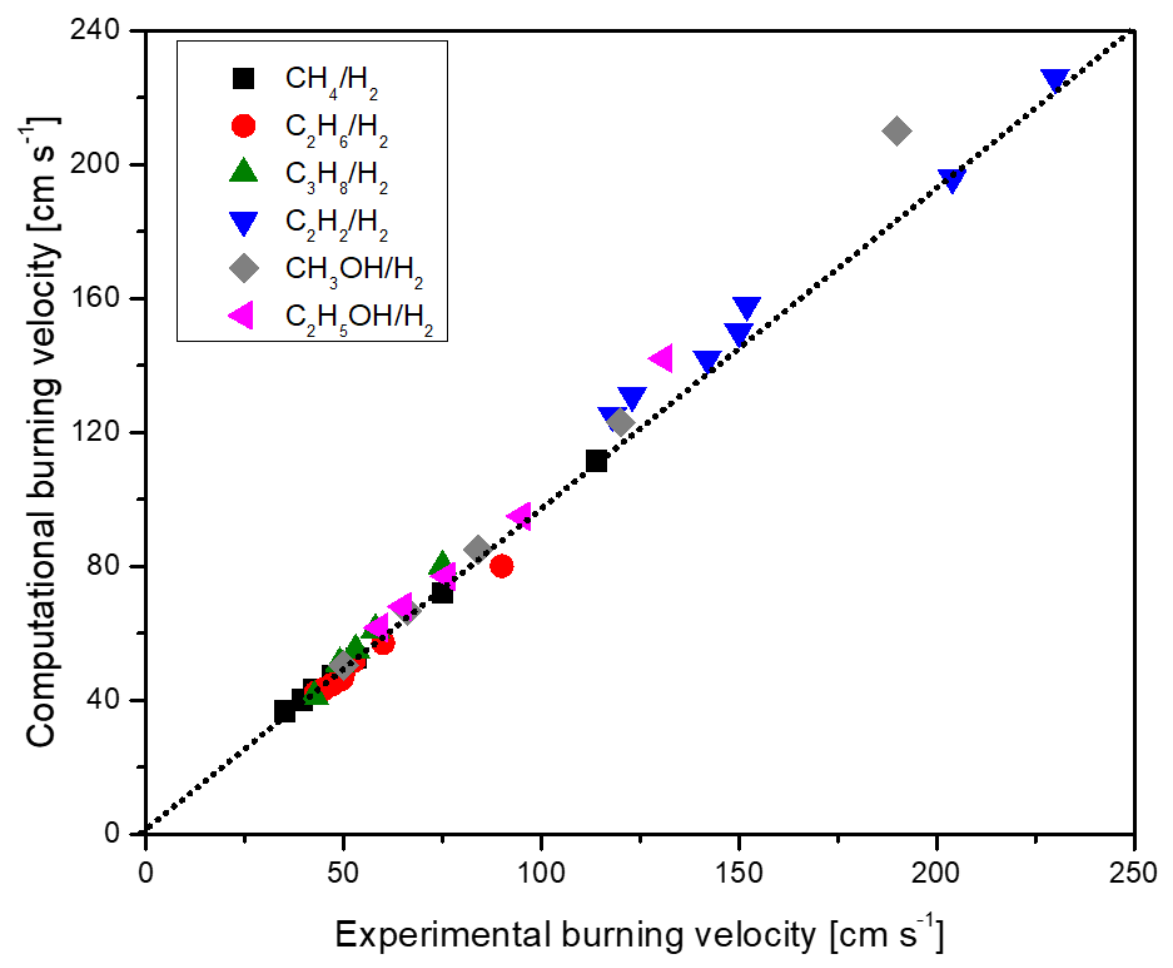

Figure 3. Comparison of experimental laminar burning velocity with its estimated values.

It can be seen from the figure that there is a satisfactory agreement between the two results for all the investigated mixtures. The observed accordance justifies further analysis of the chemistry via the adopted reaction mechanism.

To distinguish the different contributions of thermodynamic and kinetic aspects, the increases of adiabatic flame temperature and laminar burning velocity due to the hydrogen addition were reported in Figures 4 and 5.
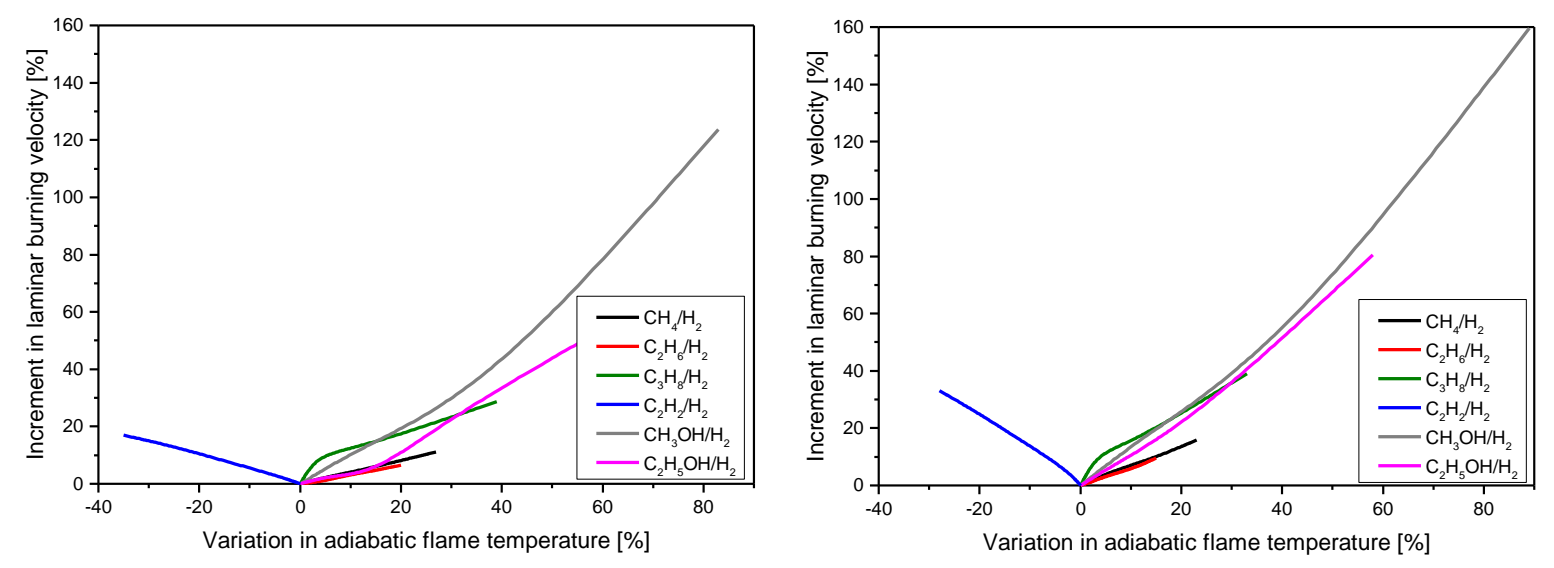

Figure 4. Increment of laminar burning velocity with increment in adiabatic flame temperature for lean (Left) and stoichiometric (Right) compositions. 

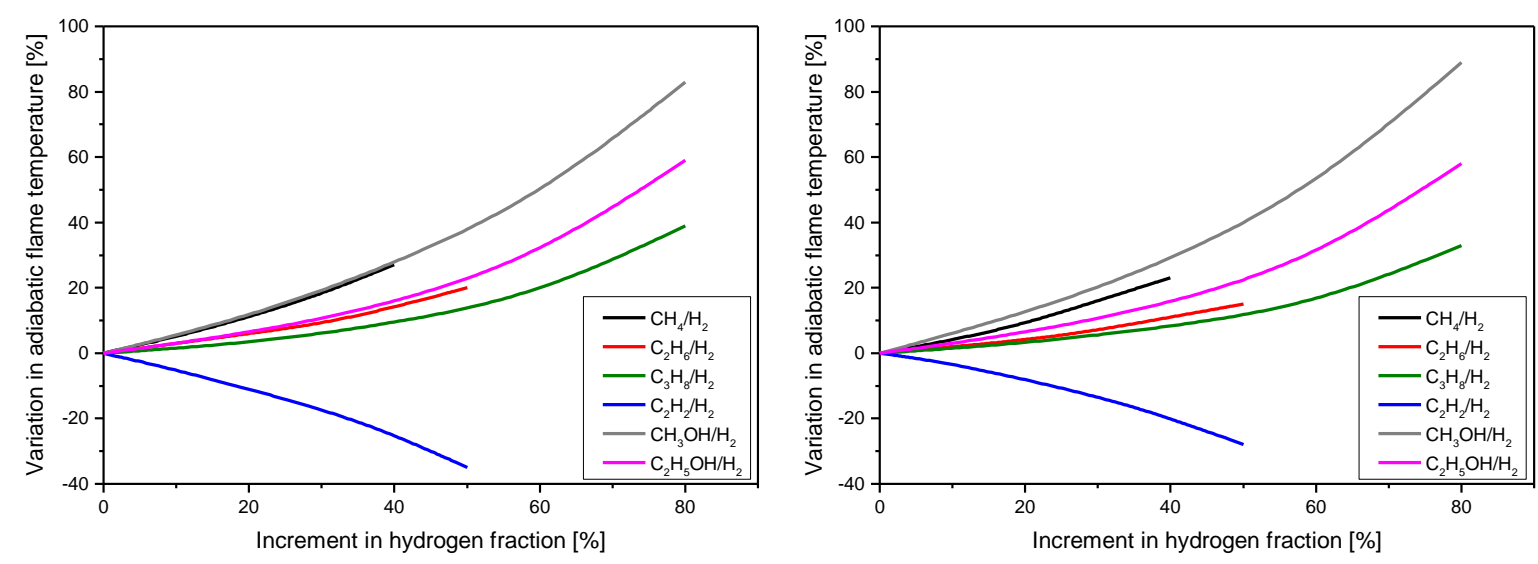

Figure 5. Variation in adiabatic flame temperature with increment in hydrogen fraction for lean (Left) and stoichiometric (Right) compositions.

Similar trends can be observed either for lean or stoichiometric compositions, meaning that the abundance of hydrogen does not alter the reaction paths of the investigated fuels. From Figures 3 and 4 , it can be observed that the increment in adiabatic flame temperature is more significant in methanol and less in the case of ethane. As a result. large enhancement in laminar burning velocity is observed for methanol and less enhancement in the case of ethane. Remarkably, the adiabatic flame temperature of all fuel mixtures increased with an increase in hydrogen fraction, except for acetylene-hydrogen-air mixtures, which show a decrease in the adiabatic flame temperature for both equivalence ratios. Similar discrepancies can be observed once the variation in adiabatic flame temperature is compared with the increase in laminar burning velocity. This means that the positive effect of hydrogen addition on the overall reactivity can be ascribed to kinetic aspects, e.g., faster ignition. Hence, the lower heat of combustion due to the absence of carbon atoms is the cause of adiabatic flame temperature reduction. In this view, it is possible to hypothesize that hydrogen mainly boosts the ignition for most of the investigated fuels and, thus, the increased reactivity leads to higher reacting temperatures. In other words, oxygen preferably reacts with hydrogen at the investigated conditions, as a result, thermodynamic and kinetic effects can be distinguished. The former is related to the decrease of the overall heat of combustion as well as the adiabatic flame temperature of the hydrogen-acetylene mixture with an increase in hydrogen content in the mixture. On the contrary, the kinetic effect is associated with an increase in the concentration of $\mathrm{H}$ radicals in the flame front region due to hydrogen addition. As a result, the $\mathrm{H}$ radicals diffuse towards the unburned, cold reactants and activate them, as testified by the increase in laminar burning velocity with hydrogen increase. The impact of hydrogen fraction on pollutants' emission is shown in Figures 6 and 7.
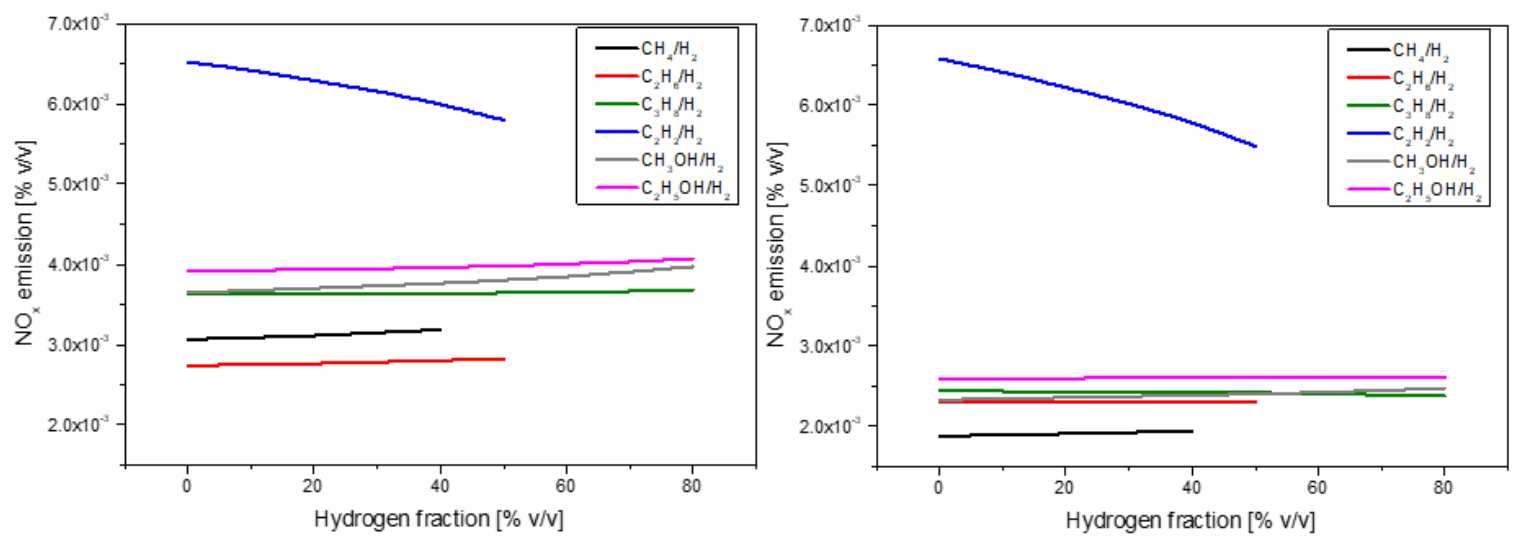

Figure 6. The impact of hydrogen fraction on $\mathrm{NO}_{X}$ at lean (Left) and stoichiometry (Right) compositions. 

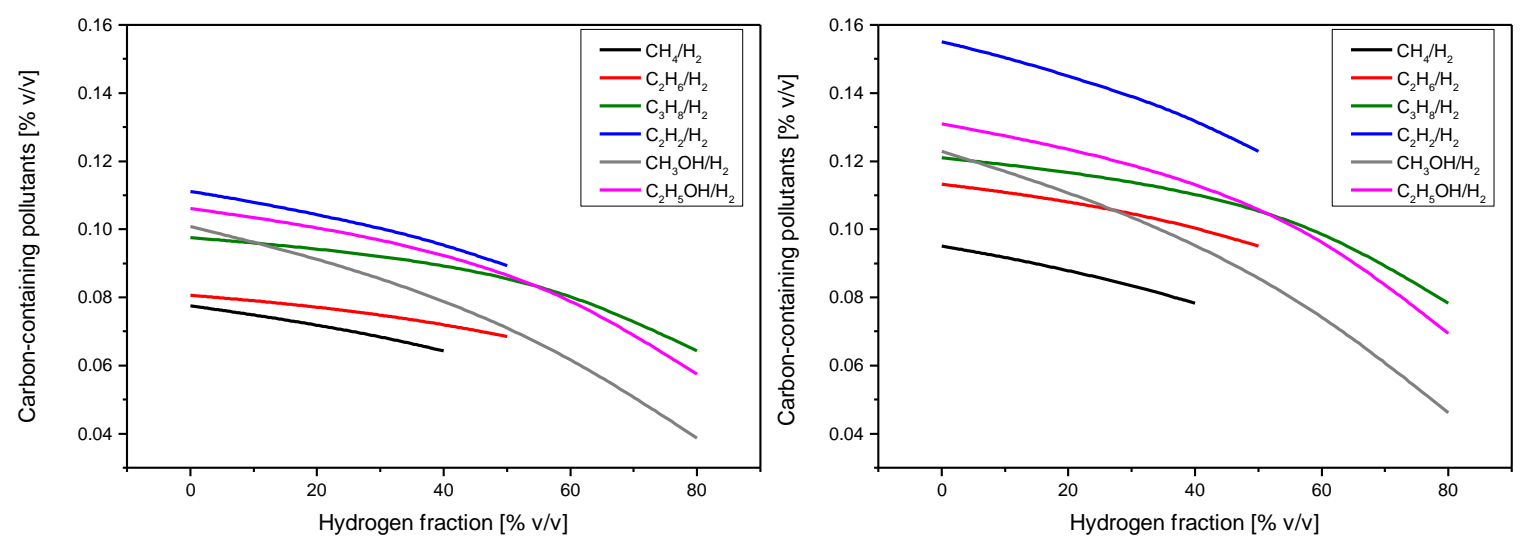

Figure 7. The impact of hydrogen fraction on carbon-containing pollutants at lean (Left) and stoichiometry (Right) compositions.

As for the adiabatic flame temperature trends, the addition of hydrogen favored the formation of $\mathrm{NO}_{X}$ at both equivalence ratios for all the investigated fuels, excluding acetylene. Comparatively, the $\mathrm{NO}_{X}$ production for methanol and ethanol is insignificantly higher than the light alkanes (methane, ethane, and propane).

This phenomenon can be attributed to the presence of the oxygenated functional group in the case of alcohol, together with the higher initial temperature considered in this analysis.

The effects of hydrogen addition on carbon-containing pollutants (e.g., $\mathrm{CO}, \mathrm{CO}_{2}$, and $\mathrm{UHC}$ ) are strongly influenced by the chemical structure of the fuel considered. Indeed, each group included in this analysis shows a peculiar trend. Regardless of the hydrogen content, their production is larger for the acetylene case. Quite obviously, this trend is related to the chemical structure of this fuel, namely a higher $\mathrm{C}-\mathrm{H}$ ratio. In this view, the comparison of methane and methanol results, together with ethane and ethanol results, offers the opportunity to evaluate the effects of the oxygenated group since both groups have the same $\mathrm{C}-\mathrm{H}$ ratio. Indeed, regardless of the initial structure, the end tail of the combustion pathway follows the formaldehyde $\left(\mathrm{CH}_{2} \mathrm{O}\right) \rightarrow$ formyl radical $(\mathrm{HCO}) \rightarrow$ carbon monoxide $(\mathrm{CO}) \rightarrow$ carbon dioxide $\left(\mathrm{CO}_{2}\right)$ route $[61,62]$. Hence, the causes of the different effect of hydrogen addition on ethane and ethanol combustion mechanisms should be attributed to the initiation steps.

It is well established that the dominant primary reaction involving alcohols oxidation is the hydrogen atom abstraction from the carbon atom $\alpha$ (i.e., the one bonded to the $\mathrm{OH}$ group), because of the different bond energies of $\mathrm{C}-\mathrm{O}$ and $\mathrm{C}-\mathrm{H}$, whereas the abstracting site does not impact the obtained radical for methane and ethane cases. For the sake of simplicity, only the $\mathrm{C}_{1}$ chemistry will be discussed in detail from now on. However, the reported discussion can be extended to a larger aliphatic chain, as well. The radicals resulting from hydrogen abstraction of methane and methanol are methyl radical $\left(\mathrm{CH}_{3}\right)$ and hydroxymethyl radical $\left(\mathrm{CH}_{2} \mathrm{OH}\right)$, respectively. The former is then oxidized to methyldioxy radical $\left(\mathrm{CH}_{3} \mathrm{OO}\right)$ and methoxy radical $\left(\mathrm{CH}_{3} \mathrm{O}\right)$, eventually forming [63], whereas the latter (i.e., hydroxymethyl radical) directly produces formaldehyde via concerted hydrogen atom abstraction and double bond formation [64]. Therefore, in both cases, it is possible to conclude that the reactions potentially affected by the presence of hydrogen are the primary hydrogen atom abstractions. Thus, confirming that the increase in combustion efficiency reported for alcohol can be attributed to improved ignition phenomena.

\section{Key Performance Indicators}

A combined analysis including environment, chemical, and maturity aspects is reported in Figure 8, which depicts the analysis of the combined effect of hydrogen fraction on the eKPI, cKPI, and $\mathrm{mKPI}$ for all species at the stoichiometric condition and $R_{i}$ equal to 0.6 , under the studied initial temperatures and pressure. 


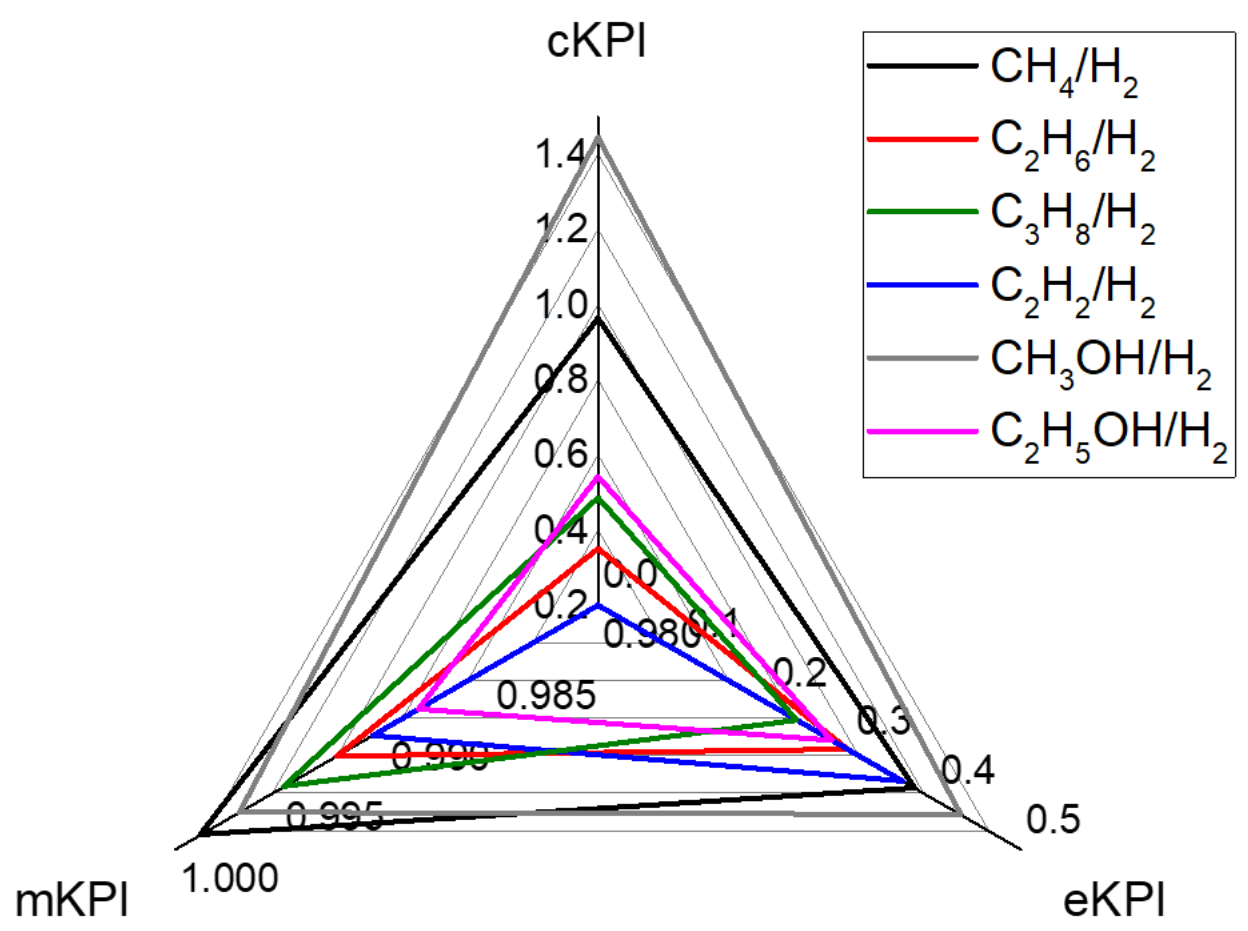

Figure 8. A comparison of energy, environmental, and maturity key performance indicators for hydrogen-containing mixtures.

As can be seen from the figure, elevated values can be observed for the maturity KPI, confirming the validity and flexibility of the adopted mechanism. This agreement represents a crucial aspect for further investigation since it provides a reliable tool for the evaluation of hydrogen addition on several fuels. On the other hand, a dedicated analysis of alcohols' chemistry should be performed to include larger species (e.g., butanol) since the lowest value is reported for ethanol. Comparing the chemical KPI it is possible to conclude that the addition of hydrogen has a larger impact on methanol and methane. It can be argued that the differences in initial temperature considered in this analysis for alcohols may cause the formation of a more activated state of the mixture, resulting in the observed trend. However, it should be recalled that cKPI is expressed as the increase in laminar burning velocity due to hydrogen addition with respect to pure fuel, evaluated at the same conditions analyzed for the corresponding hydrogen-containing mixture. Hence, the effects of initial temperature and pressure on cKPI are limited. On the contrary, the chemistry of ethane and acetylene is weakly affected by hydrogen addition, discouraging the adoption of hydrogen addition as an intensification strategy.

Although acetylene tends to produce a large number of soot precursors and $\mathrm{NO}_{\mathrm{X}}$, methane and methanol have a large impact on the environment per unit of energy produced, i.e., higher eKPIs. This observation can be related to the elevated values of $\mathrm{CO} / \mathrm{CO}_{2}$ content, meaning that the combustion efficiency is still low. Conversely, propane-hydrogen fuel mixtures showed lower eKPI under the studied conditions.

\section{Conclusions}

In this study, the effect of hydrogen fraction on hydrocarbon and alcohol mixtures has been numerically studied in terms of the laminar burning velocity and pollutant emissions. The predicted values for the laminar burning velocity are in good agreement with the experimental results reported in the literature for all fuel blends. The presence of hydrogen increases the reactivity and the adiabatic temperature of the mixtures (except for the acetylene), reduces $\mathrm{CO}, \mathrm{CO}_{2}$, and $\mathrm{UHC}$ emissions but increases the $\mathrm{NO}_{X}$ formation. 
Key performance indicators accounting for environmental impact, the maturity of the adopted model, and the chemistry effectiveness of hydrogen additions have been defined. Unequivocal conclusions cannot be drawn because of the different trends reported for these KPIs, requiring the identification of trade-offs between the reported aspects. However, their comparison represents a powerful tool for multicriteria analysis devoted to policy generation.

Author Contributions: Conceptualization, G.P. and E.S.; data curation, F.M.W. and G.P.; formal analysis, F.M.W. and G.P.; investigation, F.M.W.; methodology, F.M.W. and G.P.; resources, E.S.; software, F.M.W. and G.P.; supervision, E.S.; visualization, F.M.W. and G.P.; writing-original draft, F.M.W. and G.P.; writing-review \& editing, E.S. All authors have read and agreed to the published version of the manuscript.

Funding: This research received no external funding.

Conflicts of Interest: Authors declare no conflicts of interest.

\section{References}

1. An, Y.; Jaasim, M.; Vallinayagam, R.; Vedharaj, S.; Im, H.G.; Johansson, B. Numerical simulation of combustion and soot under partially premixed combustion of low-octane gasoline. Fuel 2018, 211, 420-431. [CrossRef]

2. Shi, Z.; Lee, C.-F.; Wu, H.; Wu, Y.; Zhang, L.; Liu, F. Optical diagnostics of low-temperature ignition and combustion characteristics of diesel/kerosene blends under cold-start conditions. Appl. Energy 2019, 251, 113307. [CrossRef]

3. Dincer, I.; Acar, C. Review and evaluation of hydrogen production methods for better sustainability. Int. J. Hydrogen Energy 2015, 40, 11094-11111. [CrossRef]

4. van Blarigan, P.; Keller, J. A hydrogen fuelled internal combustion engine designed for single speed/power operation. Int. J. Hydrogen Energy 1998, 23, 603-609. [CrossRef]

5. Akansu, S.O.; Dulger, Z.; Kahraman, N.; Veziroğlu, T.N. Internal combustion engines fueled by natural gas-hydrogen mixtures. Int. J. Hydrogen Energy 2004, 29, 1527-1539. [CrossRef]

6. Dong, C.; Zhou, Q.; Zhang, X.; Zhao, Q.; Xu, T. Experimental study on the laminar flame speed of hydrogen/natural gas/air mixtures. Front. Chem. Eng. China 2010, 4, 417-422. [CrossRef]

7. Katoch, A.; Milaa-Merino, A.; Kumar, S. Measurement of laminar burning velocity of ethanol-air mixtures at elevated temperatures. Fuel 2018, 231, 37-44. [CrossRef]

8. Liu, Y.; Lenze, B.; Leuckel, W. Investigation of the laminar and turbulent burning velocities of premixed lean and rich flames of $\mathrm{CH} 4-\mathrm{H} 2$-air mixtures. In Dynamics of Deflagrations and Reactive Systems: Flames; American Institute of Aeronautics and Astronautics, Inc.: Reston, VA, USA, 1991; pp. 259-274.

9. Salzano, E.; Pio, G.; Ricca, A.; Palma, V. The effect of a hydrogen addition to the premixed flame structure of light alkanes. Fuel 2018, 234, 1064-1070. [CrossRef]

10. Law, C.K.; Kwon, O. Effects of hydrocarbon substitution on atmospheric hydrogen-air flame propagation. Int. J. Hydrogen Energy 2004, 29, 867-879. [CrossRef]

11. Nilsson, E.J.; van Sprang, A.; Larfeldt, J.; Konnov, A.A. The comparative and combined effects of hydrogen addition on the laminar burning velocities of methane and its blends with ethane and propane. Fuel 2017, 189, 369-376. [CrossRef]

12. Dong, Y.; Vagelopoulos, C.M.; Spedding, G.R.; Egolfopoulos, F.N. Measurement of laminar flame speeds through digital particle image velocimetry: Mixtures of methane and ethane with hydrogen, oxygen, nitrogen, and helium. Proc. Combust. Inst. 2002, 29, 1419-1426. [CrossRef]

13. Tang, C.; Huang, Z.; Jin, C.; He, J.; Wang, J.; Wang, X.; Miao, H. Laminar burning velocities and combustion characteristics of propane-hydrogen-air premixed flames. Int. J. Hydrogen Energy 2008, 33, 4906-4914. [CrossRef]

14. Milton, B.; Keck, J. Laminar burning velocities in stoichiometric hydrogen and hydrogen hydrocarbon gas mixtures. Combust. Flame 1984, 58, 13-22. [CrossRef]

15. Huang, Z.; Zhang, Y.; Zeng, K.; Liu, B.; Wang, Q.; Jiang, D. Measurements of laminar burning velocities for natural gas-hydrogen-air mixtures. Combust. Flame 2006, 146, 302-311. [CrossRef] 
16. Coppens, F.; de Ruyck, J.; Konnov, A.A. The effects of composition on burning velocity and nitric oxide formation in laminar premixed flames of CH4+ H2+ O2+ N2. Combust. Flame 2007, 149, 409-417. [CrossRef]

17. Hermanns, R.; Konnov, A.A.; Bastiaans, R.; de Goey, L.; Lucka, K.; Köhne, H. Effects of temperature and composition on the laminar burning velocity of $\mathrm{CH} 4+\mathrm{H} 2+\mathrm{O} 2+\mathrm{N} 2$ flames. Fuel 2010, 89, 114-121. [CrossRef]

18. Hu, E.; Huang, Z.; He, J.; Jin, C.; Zheng, J. Experimental and numerical study on laminar burning characteristics of premixed methane-hydrogen-air flames. Int. J. Hydrogen Energy 2009, 34, 4876-4888. [CrossRef]

19. Christensen, M. Laminar Burning Velocity and Development of a Chemical Kinetic Model for Small Oxygenated Fuels. Ph.D. Thesis, Lund University, Lund, Sweden, 2016.

20. Wu, F.; Kelley, A.P.; Zhu, D.; Law, C.K. Further study on effects of hydrogen addition on laminar flame speeds of fuel-air mixtures. In Proceedings of the 7th US National Technical Meeting of the Combustion Institute, Atlanta, GA, USA, 20-23 March 2011; pp. 1336-1353.

21. Sepman, A.; Mokhov, A.; Levinsky, H. The effects of hydrogen addition on NO formation in atmospheric-pressure, fuel-rich-premixed, burner-stabilized methane, ethane and propane flames. Int. J. Hydrogen Energy 2011, 36, 4474-4481. [CrossRef]

22. Yu, G.; Law, C.K.; Wu, C. Laminar flame speeds of hydrocarbon+ air mixtures with hydrogen addition. Combust. Flame 1986, 63, 339-347. [CrossRef]

23. Kariuki, J.; Balachandran, R. Experimental investigation of dynamics of premixed acetylene-air flames in a micro-combustor. Exp. Therm. Fluid Sci. 2010, 34, 330-337. [CrossRef]

24. Balki, M.K.; Sayin, C. The effect of compression ratio on the performance, emissions and combustion of an SI (spark ignition) engine fueled with pure ethanol, methanol and unleaded gasoline. Energy 2014, 71, $194-201$. [CrossRef]

25. Chen, H.; Su, X.; He, J.; Xie, B. Investigation on combustion and emission characteristics of a common rail diesel engine fueled with diesel/n-pentanol/methanol blends. Energy 2019, 167, 297-311. [CrossRef]

26. Wei, L.; Yao, C.; Han, G.; Pan, W. Effects of methanol to diesel ratio and diesel injection timing on combustion, performance and emissions of a methanol port premixed diesel engine. Energy 2016, 95, 223-232. [CrossRef]

27. Gong, C.; Liu, Z.; Su, H.; Chen, Y.; Li, J.; Liu, F. Effect of injection strategy on cold start firing, combustion and emissions of a LPG/methanol dual-fuel spark-ignition engine. Energy 2019, 178, 126-133. [CrossRef]

28. Gong, C.; Liu, J.; Peng, L.; Liu, F. Numerical study of effect of injection and ignition timings on combustion and unregulated emissions of DISI methanol engine during cold start. Renew. Energy 2017, 112, 457-465. [CrossRef]

29. Hu, Z.; Zhang, X. Study on laminar combustion characteristic of low calorific value gas blended with hydrogen in a constant volume combustion bomb. Int. J. Hydrogen Energy 2019, 44, 487-493. [CrossRef]

30. Xiao, P.; Lee, C.-f.; Wu, H.; Liu, F. Effects of hydrogen addition on the laminar methanol-air flame under different initial temperatures. Renew. Energy 2020, 154, 209-222. [CrossRef]

31. Li, G.; Zhang, Z.; Liang, J.; Dong, F.; Li, Y.; Gao, X. Effects of hydrogen addition on the premixed laminar-flames of ethanol-air gaseous mixtures: An experimental study. Int. J. Hydrogen Energy 2012, 37, 4490-4501. [CrossRef]

32. Xiao, P.; Lee, C.-f.; Wu, H.; Akram, M.Z.; Liu, F. Impacts of hydrogen-addition on methanol-air laminar burning coupled with pressures variation effects. Energy 2019, 187, 115997. [CrossRef]

33. Korakianitis, T.; Namasivayam, A.; Crookes, R. Natural-gas fueled spark-ignition (SI) and compression-ignition (CI) engine performance and emissions. Prog. Energy Combust. Sci. 2011, 37, 89-112. [CrossRef]

34. Shin, B.; Cho, Y.; Han, D.; Song, S.; Chun, K.M. Hydrogen effects on NOx emissions and brake thermal efficiency in a diesel engine under low-temperature and heavy-EGR conditions. Int. J. Hydrogen Energy 2011, 36, 6281-6291. [CrossRef]

35. Saravanan, N.; Nagarajan, G. An experimental investigation of hydrogen-enriched air induction in a diesel engine system. Int. J. Hydrogen Energy 2008, 33, 1769-1775. [CrossRef]

36. Catapano, F.; di Iorio, S.; Magno, A.; Sementa, P.; Vaglieco, B. A comprehensive analysis of the effect of ethanol, methane and methane-hydrogen blend on the combustion process in a PFI (port fuel injection) engine. Energy 2015, 88, 101-110. [CrossRef] 
37. Kee, R.J.; Grcar, J.F.; Smooke, M.D.; Miller, J.A.; Meeks, E. PREMIX: A Fortran Program for Modeling Steady Laminar One-dimensional Premixed Flames. Sandia National Laboratories Report. Sandia Reaction Design, 11436 Sorrento Valley Road, San Diego. 1985. Available online: https://www.researchgate.net/profile/Ellen_Meeks/publication/260388319_PREMIX_a_fortran_program_ for_modeling_steady_laminar_one-dimensional_premixed_flames/links/53fe0de20cf23bb019bd249d/ PREMIX-a-fortran-program-for-modeling-steady-laminar-one-dimensional-premixed-flames.pdf (accessed on 24 July 2020).

38. Rogg, B. RUN-1DL: The Cambridge universal laminar flame code. In Technical Report CUED/A-THERMO/TR39; Department of Engineering, University of Cambridge: Cambridge, UK, 1991.

39. Bowman, C.; Frenklach, M.; Gardiner, W.; Smith, G. The GRI 3.0 Chemical Kinetic Mechanism; Gas Research Institute: Berkeley, CA, USA, 1999.

40. Sher, E.; Refael, S. A simplified reaction scheme for the combustion of hydrogen enriched methane/air flame. Combust. Sci. Technol. 1988, 59, 371-389. [CrossRef]

41. Kunioshi, N.; Fukutani, S. Fuel mixing effects on propagation of premixed flames. II. Hydrogen+ methane flames. Bull. Chem. Soc. Jpn. 1992, 65, 2573-2577. [CrossRef]

42. Hynes, R.; Mackie, J.; Masri, A. Sample Probe Measurements on a Hydrogen- Ethane- Air2-H-Heptafluoropropane Flame. Energy Fuels 1999, 13, 485-492. [CrossRef]

43. Qin, Z.; Lissianski, V.V.; Yang, H.; Gardiner, W.C.; Davis, S.G.; Wang, H. Combustion chemistry of propane: A case study of detailed reaction mechanism optimization. Proc. Combust. Inst. 2000, 28, 1663-1669. [CrossRef]

44. Al-Hamamre, Z.; Yamin, J. The effect of hydrogen addition on premixed laminar acetylene-hydrogen-air and ethanol-hydrogen-air flames. Int. J. Hydrogen Energy 2013, 38, 7499-7509. [CrossRef]

45. Burke, U.; Metcalfe, W.K.; Burke, S.M.; Heufer, K.A.; Dagaut, P.; Curran, H.J. A detailed chemical kinetic modeling, ignition delay time and jet-stirred reactor study of methanol oxidation. Combust. Flame 2016, 165, 125-136. [CrossRef]

46. Gong, C.; Li, Z.; Li, D.; Liu, J.; Si, X.; Yu, J.; Huang, W.; Liu, F.; Han, Y. Numerical investigation of hydrogen addition effects on methanol-air mixtures combustion in premixed laminar flames under lean burn conditions. Renew. Energy 2018, 127, 56-63. [CrossRef]

47. Gong, C.; Li, D.; Li, Z.; Liu, F. Numerical study on combustion and emission in a DISI methanol engine with hydrogen addition. Int. J. Hydrogen Energy 2016, 41, 647-655. [CrossRef]

48. Ji, C.; Yang, J.; Liu, X.; Zhang, B.; Wang, S.; Gao, B. A quasi-dimensional model for combustion performance prediction of an SI hydrogen-enriched methanol engine. Int. J. Hydrogen Energy 2016, 41, 17676-17686. [CrossRef]

49. Pio, G.; Barba, D.; Palma, V.; Salzano, E. A numerical study on the effect of temperature and composition on the flammability of methane-hydrogen sulfide mixtures. Combust. Sci. Technol. 2019, 191, 1541-1557. [CrossRef]

50. Pio, G.; Salzano, E. Evaluation of safety parameters of light alkenes by means of detailed kinetic models. Process. Saf. Environ. Prot. 2018, 119, 131-137. [CrossRef]

51. Pio, G.; Salzano, E. Flammability parameters of liquified natural gas. J. Loss Prev. Process. Ind. 2018, 56, 424-429. [CrossRef]

52. Burcat, A.; Ruscic, B. Third Millenium Ideal Gas and Condensed Phase Thermochemical Database for Combustion (with Update from Active Thermochemical Tables); Argonne National Lab. (ANL): Argonne, IL, USA, 2005.

53. Pio, G.; Palma, V.; Salzano, E. Comparison and validation of detailed kinetic models for the oxidation of light alkenes. Ind. Eng. Chem. Res. 2018, 57, 7130-7135. [CrossRef]

54. Goodwin, D. An open-source, extensible software suite for CVD process simulation. Chem. Vap. Depos. Xvi Eurocvd 2003, 14, 2003-2008.

55. Pio, G.; Salzano, E. The effect of ultra-low temperature on the flammability limits of a methane/air/diluent mixtures. J. Hazard. Mater. 2019, 362, 224-229. [CrossRef]

56. Pio, G.; Salzano, E. Implementation of gas-phase kinetic model for the optimization of the ethylene oxide production. Chem. Eng. Sci. 2020, 212, 115331. [CrossRef]

57. Sreedharan, P. Recent estimates of energy efficiency potential in the USA. Energy Effic. 2013, 6, 433-445. [CrossRef] 
58. Kido, H.; Huang, S.; Tanoue, K.; Nitta, T. Improving the combustion performance of lean hydrocarbon mixtures by hydrogen addition. JSAE Rev. 1994, 15, 165-170. [CrossRef]

59. Teng, F. The Effect of Hydrogen Concentration on the Flame Stability and Laminar Burning Velocity of Hydrogen-Hydrocarbon-Carbon Dioxide Mixtures; University of Sheffield: Sheffield, UK, 2014.

60. Battin-Leclerc, F. Detailed chemical kinetic models for the low-temperature combustion of hydrocarbons with application to gasoline and diesel fuel surrogates. Prog. Energy Combust. Sci. 2008, 34, 440-498. [CrossRef]

61. Curran, H.J. Developing detailed chemical kinetic mechanisms for fuel combustion. Proc. Combust. Inst. 2019, 37, 57-81. [CrossRef]

62. Sarathy, S.M.; Vranckx, S.; Yasunaga, K.; Mehl, M.; Oßwald, P.; Metcalfe, W.K.; Westbrook, C.K.; Pitz, W.J.; Kohse-Höinghaus, K.; Fernandes, R.X.; et al. A comprehensive chemical kinetic combustion model for the four butanol isomers. Combust. Flame 2012, 159, 2028-2055. [CrossRef]

63. Warnatz, J. The structure of laminar alkane-, alkene-, and acetylene flames. Symp. (Int.) Combust. 1981, 18, 369-384. [CrossRef]

64. Yalamanchili, S.; Sirignano, W.; Seiser, R.; Seshadri, K. Reduced methanol kinetic mechanisms for combustion applications Combust. Flame 2005, 142, 258-265. [CrossRef]

(C) 2020 by the authors. Licensee MDPI, Basel, Switzerland. This article is an open access article distributed under the terms and conditions of the Creative Commons Attribution (CC BY) license (http://creativecommons.org/licenses/by/4.0/). 